\title{
Artikel
}

\section{Het standstillbeginsel en de uitvoering van het VN-Verdrag Handicap}

\author{
Mr. drs. E. Dijkstra*
}

\section{Inleiding}

De belofte van het moderne mensenrechtenkader - universele rechten voor eenieder - wordt sinds decennia met specifieke convenanten ook naderbij gebracht voor degenen die deze rechten tot dan toe niet ten volle konden genieten. ${ }^{1}$ Een groep mensen voor wie de courante interpretatie van de algemene mensenrechtenverdragen tekortschoot, zijn mensen met een functiebeperking. Met het oog op de bestendigheid van hun weinig benijdenswaardige maatschappelijke positie zijn de reeds bestaande mensenrechtelijke verplichtingen daarom verder uitgewerkt in het Internationaal Verdrag inzake de Rechten van Personen met een Handicap (VN-verdrag Handicap). ${ }^{2}$ De rechten die in dit verdrag vervat zijn, verplichten de verdragsstaten om volwaardige maatschappelijke deelname en zelfstandige levenskeuzes van mensen met een functiebeperking, op gelijke voet met relatief gezonde medemensen, te faciliteren. ${ }^{3}$ Veel van de veranderingen die de in dit verdrag gecodificeerde rechten beogen, kunnen echter niet van de ene op de andere dag plaatsvinden. Dit maakt deze rechten echter

Mr. drs. E. (Erwin) Dijkstra is docent/onderzoeker aan de Faculteit der Rechtsgeleerdheid van de Universiteit Leiden.

1. P. Thornberry, The international convention on the elimination of all forms of racial discrimination: a commentary, Oxford: Oxford University Press 2018, p. 3.

2. E. Dijkstra, 'De coronacrisis noopt tot meer expliciete aandacht van de Nederlandse staat voor het VN-verdrag handicap', NTM/NJCM-Bulletin 2020/45, afl. 3, p. 377 (hierna: Dijkstra 2020a)

3. E. Dijkstra, 'Wanneer je leven bepaald wordt door de wet - over handicap, regelgeving en identiteit, Handicap \& Recht 2020/5, afl. 2, p. 41-46 (hierna: Dijkstra 2020b). niet vrijblijvend. In het internationale recht - maar niet alleen daar - vinden we namelijk de norm dat vanaf het moment dat een staat zich verbindt tot bepaalde verplichtingen in dergelijke verdragen, deze 'geen maatregelen mag nemen die afbreuk doen aan het doel van de bepaling of een achteruitgang betekenen voor de rechtsbescherming, ${ }^{4}$ Deze norm staat wel bekend als het standstillbeginsel of het non-regressie-beginsel. ${ }^{5}$

In deze bijdrage zal ik dit beginsel kort inleiden om vervolgens te onderzoeken in hoeverre het een rol speelt bij de Nederlandse regelgeving en jurisprudentie inzake de uitvoering van het $\mathrm{VN}$-verdrag Handicap. De kleine rol van het standstillbeginsel die uit dit onderzoek naar voren komt, geeft aanleiding voor de vervolgvraag in hoeverre recente juridische ontwikkelingen betreffende mensen met een functiebeperking niet botsen met dit beginsel. Uit een tweetal recente botsingen, die de toegankelijkheid van kieslokalen en de invoering van de Participatiewet betreffen, trek ik de conclusie dat er in de toekomst meer aandacht aan het standstillprincipe moet worden geschonken bij de uitvoering van het $\mathrm{VN}$ verdrag Handicap. Dit zal echter niet zomaar gebeuren, want Nederland heeft zich vooralsnog niet aangesloten bij het optionele protocol bij het VN-verdrag Handicap. Dit protocol zou klagen over eventuele schendingen van het standstillbeginsel bij het corresponderende $\mathrm{VN}$ comité mogelijk maken. ${ }^{6}$

4. A. Thienpont \& C. Herman, Mensenrechten: een kennismaking, Gent: Druk in de Weer 2009, p. 15. Over dergelijke normative general principles als bron van internationaal recht, zie: M. Koskenniemi, Sources of international law, Londen: Routledge 2000, p. 364-365.

5. L. Collins, 'Principle of non-regression', in: J.-F. Morin \& A. Orsini (red.) Essential concepts of global environmental governance, Londen: Routledge 2020, p. 205.

6. L. Manca, 'Article 33 [national implementation and monitoring]', in: V. della Fina, R. Cera \& G. Palmisano (red.), The UN-convention on the 


\section{Het standstillbeginsel}

Het standstillbeginsel is niet even relevant voor alle mensenrechtelijke verplichtingen. In dat kader kan het handig zijn om uit te gaan van de gebruikelijke indeling van de bestaande rechten, zoals deze in verdragen en nationale regelgeving te vinden zijn, in twee generaties: de eerste generatie politieke en burgerlijke rechten en de tweede generatie economische, sociale en culturele rechten. ${ }^{7}$ Deze verdeling is niet zonder critici: de meeste verdragen omvatten bijvoorbeeld rechten die zowel tot de eerste als de tweede generatie behoren en bij alle mensenrechtelijke verplichtingen - of zij nu politiek, burgerlijk, sociaal, economisch of cultureel van aard zijn - wordt verwacht van staten dat zij zich van bepaalde acties onthouden, bepaalde zaken regelen en meer in het algemeen individuele burgers beschermen. ${ }^{8}$ Toch zijn er verschillen aan te wijzen tussen beide generaties rechten en deze zijn relevant voor het standstillbeginsel. De meeste burgerlijke en politieke rechten hebben directe werking: zij dienen onmiddellijk en volledig gerespecteerd te worden en als dit niet gebeurt, kan de burger dit afdwingen via de rechter. ${ }^{9}$ Een hypothetische staat die zich nu, na de inwerkingtreding, ansluit bij het Internationaal Verdrag inzake burgerrechten en politieke rechten (IVBPR), zal onmiddellijk moeten stoppen met eventuele martelpraktijken. ${ }^{10}$ En als die staat bepaalde mensen deelname aan het politieke leven ontzegt, zal hij dit meteen moeten remediëren. ${ }^{11}$ Veel van de rechten die tot de tweede generatie economische, sociale en culturele rechten worden gerekend, zijn echter algemener geformuleerd en concrete doelen met een dito tijdpad ontbreken vaak. ${ }^{12}$ Dit ontslaat een verdragsstaat echter niet van de verplichtingen die uit deze tweede generatie rechten voortvloeien. Ook zonder einddatum en uitputtende eisenlijst zal hij bijvoorbeeld, ex artikel 12 van het Internationaal Verdrag inzake economische, sociale en culturele rechten (IVESCR), moeten werken aan de opbouw van een functionerende en voldoende toegeruste en inclusieve publieke gezondheidszorg - die ten minste in een minimum aan voorzieningen voorziet. ${ }^{13}$ We zien dan ook dat diverse

rights of persons with disabilities: a commentary, Cham: Springer 2017, p. 592-593.

7. Vaak worden bij deze indeling ook voorstellen voor een derde generatie aan groepsrechten genoemd. Het enige gerealiseerde groepsrecht is momenteel het recht op zelfbeschikking, zie: V. van Dyke, 'Collective entities and moral rights: problems in liberal-democratic thought', The Journal of Politics 1982/44, afl. 1, p. 185

8. A.J. Nieuwenhuis, M. den Heijer \& A.W. Hins, Hoofdstukken grondrechten, Nijmegen: Ars Aequi Libri 2017, p. 26, 146.

9. Thienpont \& Herman 2009, p. 13.

10. Art. 7 IVBPR, zie: P.M. Taylor, A commentary on the International covenant on civil and political rights: the UN human rights committee's monitoring of ICCPR rights, Cambridge: Cambridge University Press, 2020, p. 175.

11. Art. 25 IVBPR, zie: Taylor 2020, p. 693

12. J. Gordon, 'The concept of human rights: the history and meaning of its politicization', Brooklyn Journal of International Law 1998/23, afl. 3, p. $696,709-710$

13. Ben Saul, David Kinley and Jacqueline Mowbray, The International Covenant on economic, social and cultural rights: commentary, cases,
VN-organen hebben vastgesteld dat met rechten van de tweede generatie, ook wanneer zij zich vooral richten op de lange(re) termijn, eveneens niet gemarchandeerd kan worden. Onder andere de Algemene Vergadering van de $\mathrm{VN}$ en het $\mathrm{VN}$-comité voor Economische, Sociale en Culturele Rechten hebben in dit kader de noodzaak van voortdurende vooruitgang en een verbod op achteruitgang benadrukt. ${ }^{14}$ Hooguit kan er - en dan louter tot op zekere hoogte - rekening worden gehouden met de hulpmiddelen die een verdragsstaat ter beschikking staan. ${ }^{15}$ Deze combinatie van gebod en verbod voor mensenrechtelijke verplichtingen op de lange(re) termijn, die meestal voortvloeien uit sociale, economische en culturele rechten, is in een notendop het standstillbeginsel.

Het standstillbeginsel, zoals ik dat hierboven in vogelvlucht beschreef, is als norm zowel relevant voor het internationale recht als voor nationale constituties en wetten. ${ }^{16}$ Een voorbeeld is artikel 13 IVESCR: verdragsstaten moeten stappen zetten richting kosteloos (primair) onderwijs en onderweg - of als dit eenmaal bereikt is - kunnen de kosten niet weer worden verhoogd. ${ }^{17}$ In sommige Europese landen is het standstillbeginsel daarnaast opgenomen in nationale regelgeving, als bodem onder sociale voorzieningen en als aansporing tot vooruitgang. ${ }^{18}$ Een voorbeeld dicht bij huis is de veronderstelde anwezigheid van het standstillbeginsel in artikel 23 van de Belgische Grondwet. ${ }^{19}$ Het beginsel is eveneens van toenemend belang voor het milieu- en omgevingsrecht. Hier wordt het vaak aangeduid als het non-regressie-beginsel. ${ }^{20}$ Algemeen wordt aangenomen dat het standstillbeginsel ook bij het VN-verdrag Handicap een rol speelt en dat dit als zodanig is geformuleerd in artikel 4 lid 1 sub a tot en met $\mathrm{d}$ van dit verdrag. ${ }^{21}$

and materials, Oxford: Oxford University Press 2014, p. 978, 980, 985, 1010-1011; E. Dijkstra, 'Addressing problems instead of diagnoses: reimagining liberalism regarding disability and public health', Netherlands Journal of Legal Philosophy 2021/20, afl. 1, ter perse.

14. UN General Assembly, Universal Declaration of human rights, 10 December 1948, 217 A (III); UN Committee on Economic, Social and Cultural Rights (CESCR), General comment no. 3: the nature of states parties obligations (1990), par. 9

15. Idem, par. 10, par. 12 .

16. G.S. Katrougalos, "European "social states" and the USA: an ocean apart?', European Constitutional Law Review 2008/4, afl. 2, p. 239. Zie uitgebreider: I. Hachez, Le principe de standstill dans le droit des droits fondamentaux, Brussel: Bruylant 2008.

17. Thienpont \& Herman 2009, p. 15.

18. Katrougalos 2008, p. 239-240.

19. D. Dumont, 'Dégressivité accrue des allocations de chômage versus principe de standstill', Journal de Tribunaux 2013/17, afl. 39, p. 769-776. Voor enkele nuances betreffende de veronderstelde aanwezigheid van het standstillbeginsel in dit grondwetsartikel, zie: M. Stroobant, 'Artikel 23 van de Grondwet en de armoedeproblematiek', in: F. de Boe (red.), Armoede - waardigheid - mensenrechten: 10 jaar samenwerkingsakkoord 1998-2008, Brussel: CGKR 2008, p. 43, 47.

20. Collins 2020, p. 205.

21. V. della Fina, 'Article 4 [general obligations]', in: V. della Fina, R. Cera \& G. Palmisano (red.), The UN-convention on the rights of persons with disabilities: a commentary, Cham: Springer 2017, p. 145. 
Want ook het VN-verdrag Handicap omvat zowel onmiddellijke verplichtingen, zoals wetten die discriminatie verbieden en het kiesrecht voor mensen met een functiebeperking, als langetermijnverplichtingen, zoals de toegankelijkheid van het verkiezingsproces en het recht op een open, inclusieve en toegankelijke arbeidsmarkt. ${ }^{22}$ Zeker met betrekking tot deze laatste categorie verplichtingen - min of meer de rechten die behoren tot de tweede generatie - én de algemene doelen van het VN-verdrag Handicap geldt dat hetgeen dat wordt beoogd en opgedragen 'gradueel [mag] worden bereikt, maar onderwijl mogen de verdragsstaten niet tegen de verplichtingen van het verdrag ingaan'. ${ }^{23}$

\section{Het standstillbeginsel in Nederland}

Deze korte inleiding op het standstillbeginsel brengt mij op de vraag of en hoe dit beginsel hier te lande functioneert met betrekking tot het $\mathrm{VN}$-verdrag Handicap. Het standstillbeginsel is in ieder geval geen onbekende op Nederlandse bodem. Als men naar de verschillende formuleringen van dit beginsel zoekt in de verzamelde jurisprudentie in de database Legal Intelligence, dan vindt men iets minder dan duizend rechterlijke uitspraken en dat op alle niveaus van de rechtspleging. ${ }^{24}$ Daarnaast komt het beginsel veelvuldig voor in andere juridisch relevante documenten, van ministeriële besluiten tot Kamerstukken. ${ }^{25}$ De overgrote meerderheid van de jurisprudentie en andere juridisch relevante documenten betreft echter het milieu- en omgevingsrecht, het belastingrecht, het vreemdelingenrecht en het EUrecht. Aangaande het milieu, de belastingen, migratieen asielkwesties en de EU heeft men het belang en de betekenis van dit beginsel dus goed op het netvlies, maar bij andere rechtsgebieden lijkt dat minder het geval te zijn - ondanks sporadische uitzonderingen. ${ }^{26}$

Dit laatste geldt ook voor het VN-verdrag Handicap: zowel in de rechtspraak als in andere juridisch relevante documenten wordt het standstillprincipe zelden

22. R. Cera, 'Article 5 [equality and non-discrimination]' in: V. della Fina, R. Cera \& G. Palmisano (red.), The UN-convention on the rights of persons with disabilities: a commentary, Cham: Springer 2017, p. 165-166 (hierna: Cera 2017a); R. Cera, 'Article 29 [participation in political and public life]', in: V. della Fina, R. Cera \& G. Palmisano (red.), The UNconvention on the rights of persons with disabilities: a commentary, Cham: Springer 2017, p. 530 (hierna: Cera 2017b); M.V. Liisberg, 'Article 27 [work and employment]', in: V. della Fina, R. Cera \& G. Palmisano (red.), The UN-convention on the rights of persons with disabilities: a commentary, Cham: Springer 2017, p. 498-499.

23. Dijkstra 2020b, p. 45

24. Geraadpleegd op 8 maart 2021. Uitspraken die gingen over standstillbepalingen of standstillclausules in contracten zijn niet meegerekend.

25. Wederom gezocht in Legal Intelligence. Geraadpleegd op 8 maart 2021.

26. Vanwege het beperkte aantal woorden dat mij voor deze bijdrage ter beschikking staat, beperk ik mij tot een tweetal recente voorbeelden: Kamerstukken I/ 2016/17, 21501-31, nr. 427, p. 5; Kamerstukken II 2014/15, 34000-XVI, nr. 125, p. 7, 17. genoemd in verband met de uitvoering van het verdrag. Hier zien we weer het verschil tussen grofweg politieke en burgerlijke rechten aan de ene kant en economische, sociale en culturele rechten aan de andere kant. Voorafgaand aan en ten tijde van de ratificatie van het verdrag in 2016 werd er door de wetgever vooral voortgang geboekt op het gebied van de hierboven reeds uitgewerkte eerste generatie rechten. Hiertoe werden onder andere de Kieswet en de Wet gelijke behandeling op grond van handicap of chronische ziekte $(\mathrm{Wgbh} / \mathrm{cz})$ aangepast. ${ }^{27} \mathrm{Om}$ de Kieswet als voorbeeld te nemen: sinds 2008 heeft elke Nederlander van 18 jaar of ouder kiesrecht - mits zij niet door de rechter uit het kiesrecht zijn ontzet. ${ }^{28}$ In de immer voortdurende discussie over de mogelijkheid om binnen het moderne mensenrechtenkader personen met een verstandelijke functiebeperking uit te sluiten van het kiesrecht, heeft Nederland dus een duidelijke lijn gekozen en wordt een dergelijke 'categorale uitsluiting van (...) het kiesrecht niet (meer) gerechtvaardigd [gevonden]'. ${ }^{29}$

Bij deze wetswijzigingen werd er ook aandacht besteed aan de lange termijn-doelen en -verplichtingen waarop het standstillprincipe van toepassing kan zijn. Men kan echter anvoeren dat deze aandacht wellicht te beperkt was. Ik geef drie voorbeelden: De verplichting om stemlokalen toegankelijk te maken, bleef toentertijd relatief beperkt; hulp in het stemhokje is alleen beschikbaar voor mensen met een lichamelijke functiebeperking; en de algemene toegankelijkheid die de $\mathrm{Wgbh} / \mathrm{cz}$ eiste, werd relatief vrijblijvend geformuleerd in vergelijking met de veelomvattend geformuleerde verplichting in het verdrag. ${ }^{30}$ Bij geen van deze kwesties, noch bij de meeste andere langetermijnverplichtingen die voortvloeien uit het VN-verdrag Handicap, kwam het standstillprincipe (expliciet) aan bod. Dit zien we ook terug in de jurisprudentie, hoewel er in de rechtspraak naar alle waarschijnlijkheid wel ruimte is voor toepassing van

27. Stb. 2016, 215

28. Stb. 2008, 272; Minister van Binnenlandse Zaken, 'Toegankelijkheid Verkiezingsproces', Kamerbrief 20 maart 2018, p. 1-2.

29. Kamerbrief 20 maart 2018, p. 2; Cera 2017b, p. 531. De algemeen geformuleerde uitsluitingsmogelijkheid voor mensen met een verstandelijke functiebeperking in General Comment 25 bij het IVBPR is in 2011 genuanceerd door de VN-Mensenrechtencommissaris, zie: UN Human Rights Committee (HRC), CCPR General comment no. 25: article 25 (participation in public affairs and the right to vote), the right to participate in public affairs, voting rights and the right of equal access to public service (1996), par. 4; UN Human Rights Council, Thematic study by the Office of the United Nations High Commissioner for Human Rights on participation in political and public life by persons with disabilities (2011), par. 28. Paul Taylor gaat in zijn recente commentaar op het IVPBR echter nog uit van General Comment 25, zie: Taylor 2020, p. 698

30. J.L. Hoegen Dijkhof, 'Stemrecht in het echt: onderzoek naar de toegankelijkheid van verkiezingen voor mensen met een beperking', Handicap \& Recht 2017/2, afl. 2, p. 48; A. van Eijndhoven \& S. Goudsmit, 'Mensen met een verstandelijke beperking hebben recht op ondersteuning bij stemmen', NJB 2017/92, afl. 10, p. 668.; C.A. Goudsmit, ‘Uitbreiding WGBH/CZ met goederen en diensten: Rechtsbescherming van personen met een handicap neemt toe', Handicap \& Recht 2016/1, afl. 1, p. 7; F. Seatzu, 'Article 9 [accessibility]', in: V. della Fina, R. Cera \& G. Palmisano (red.), The UN-convention on the rights of persons with disabilities: a commentary, Cham: Springer 2017, p. 228 
normen als het standstillbeginsel bij toetsing aan het VN-verdrag Handicap. ${ }^{31}$ Een welkome uitzondering op deze verwaarlozing wordt gevormd door een relatief klein aantal Kamervragen, Kamerdebatten en amendementen, vooral inzake de Wet maatschappelijke ondersteuning (Wmo) en de Participatiewet. ${ }^{32}$ Geeft de status als ondergeschoven kindje van de lange termijn-verplichtingen uit het VN-verdrag Handicap dan aanleiding om met het standstillbeginsel in de hand de Nederlandse staat te vragen om bepaalde zaken te veranderen en zich van andere veranderingen te onthouden, dan wel bepaalde veranderingen ongedaan te maken? Zoals bij de meeste juridisch-theoretische vragen is het antwoord: dat hangt ervan af.

\section{Is er een rol weggelegd voor het standstillbeginsel?}

Het standstillbeginsel lijkt dus een ondergeschikte rol te spelen bij veranderingen in de wet- en regelgeving die te maken (kan) hebben met het toepassingsgebied van het VN-verdrag Handicap. Sterker nog, het komt zelden aan de orde. Is er, gezien de grote veranderingen inzake de maatschappelijke positie van mensen met een functiebeperking van de afgelopen jaren, reden om dit beginsel beter onder de aandacht te brengen? Er zijn aanleidingen om hierover na te denken. Eén van deze aanleidingen is de schaduwrapportage die in 2019 aan het VN-Mensenrechtencomité in Genève werd aangeboden. Volgens deze rapportage is de situatie voor mensen met een functiebeperking in Nederland aantoonbaar verslechterd. ${ }^{33}$ Afhankelijk van de omstandigheden waaronder deze verslechteringen hebben plaatsgevonden kan het standstillbeginsel een nuttige leidraad voor reflectie en hervorming bieden.

Of het standstillbeginsel van toepassing is op veranderingen in wet- en regelgeving hangt af van de interpretatie van de verdragsverplichtingen en van het tijdstip van de invoering van de veranderingen. ${ }^{34} \mathrm{Om}$ met dat laatste te beginnen: men moet het moment van ondertekening en ratificatie van elkaar onderscheiden. ${ }^{35} \mathrm{Na}$ de ratificatie is een verdragsstaat gehouden om het verdrag gewe-

31. G.J.W. Pulles, "“Een verdrag met potentieel vérstrekkende gevolgen": de toepassing van het VN-verdrag Handicap door de Nederlandse rechter', Handicap \& Recht 2017/2, afl. 1, p. 8.

32. Kamerstukken II 2013/14, 33841, nr. 167, p. 8; Kamerstukken I 2013/14, 33841, G, p. 111-112; Kamerstukken I/ 2014/15, 33992(R2034), nr. 6, p. 92; Kamerstukken // 2014/15, 33992-(R2034), nr. 7, p. 46; Kamerstukken I/ 2018/19, 35174, nr. 9, p. 3.

33. M. Visser, 'Nederland krijgt een onvoldoende voor de positie van mensen met een beperking', Trouw 3 december 2019, trouw.nl; B. van der Voort, 'Mensen met handicap slachtoffer rijksbeleid', Reformatorisch Dagblad 18 december 2019, Forum, p. 18-19.

34. A. Aust, Modern treaty law and practice, Cambridge: Cambridge University Press 2007, p. 169.

35. F. Hoffmeister, 'Article 14: Consent to be bound by a treaty expressed by ratification, acceptance or approval', in: O. Dörr \& K. Schmalenbach (red.), Vienna convention on the law of treaties: a commentary, Cham: Springer 2018, p. 199-200; Aust 2007, p. 103-105. tensvol uit te voeren; het standstillbeginsel is echter reeds van toepassing bij de ondertekening. ${ }^{36}$ Het VNverdrag Handicap is in 2006 ondertekend en Nederland heeft het in 2016 geratificeerd. ${ }^{37}$ De grootste veranderingen van de afgelopen jaren - zoals de invoering van de Participatiewet en de herziening van de Wmo en de Wajong - vonden dus plaats vóór dit moment van ratificatie. ${ }^{38}$ Dit laat ons dus niet helemaal met lege handen staan. Ten eerste kunnen de genoemde veranderingen tussen het tekenen van het verdrag en de ratificatie alsnog strijdig zijn met het standstillbeginsel. Ten tweede kan men stellen dat de algemene doelen van het VN-verdrag - als een soort overkoepelend standstillbeginsel - vereisen dat de weg naar volwaardige maatschappelijke deelname en zelfstandige levenskeuzes voor mensen met een functiebeperking zonder omwegen gevolgd wordt en dat deze doelen ook niet vóór de uiteindelijke ratificatie met voeten kunnen worden getreden. Aan de hand van twee voorbeelden - de toegankelijkheid van het verkiezingsproces en de Participatiewet - zal ik illustreren dat het standstillprincipe in ieder geval in dezen werd verwaarloosd en daarom wellicht een prominentere plaats moet krijgen in de discussies en besluitvorming omtrent veranderingen van soortgelijke wet- en regelgeving. Bij het bespreken van deze voorbeelden zal ook de kwestie van de mogelijke interpretaties van de verdragsverplichtingen inzake het standstillbeginsel aan de orde komen.

\subsection{Verkiezingen, COVID-19 en mensen met een functiebeperking}

Zoals reeds werd aangestipt, omvat het gelijke kiesrecht voor mensen met een functiebeperking, zoals dat (mede) gecodificeerd is in artikel $29 \mathrm{VN}$-verdrag Handicap, zowel onmiddellijke als langetermijnverplichtingen. De onmiddellijke verplichting - dat alle mensen, inclusief degenen met een mentale functiebeperking, mogen stemmen en verkozen worden - is hierboven al aan de orde geweest. De langetermijnverplichting - oftewel de toegankelijkheid van het verkiezingsproces - zal nu dienen als voorbeeld van de relevantie van het standstillbeginsel. ${ }^{39}$ Dit voorbeeld kent twee aspecten: de nominale vooruitgang inzake de toegankelijkheid van de stemlokalen en de teruggang in toegankelijkheid tijdens de Tweede Kamerverkiezingen van 17 maart 2021, die plaatsvonden tijdens de wereldwijde coronacrisis.

36. Della Vina 2017, p. 145; Ch.-F. Lo, Treaty interpretation under the Vienna Convention on the law of treaties: a new round of codification, Cham: Springer 2017, p. 188-189, 292. Dit is bevestigd door de regering, zie: Kamerstukken // 2013/14, 33841, nr. 167, p. 8

37. J.E. Goldschmidt, 'Van gelijke behandeling naar inclusie: het VN-verdrag inzake de rechten van personen met een handicap', VN-Forum 2016/28, afl. 1/2, p. 8.

38. I.A.M. Boetzelaer-Gulyas, Basisboek sociale zekerheid 2021, Deventer: Wolters Kluwer 2020, p. 127, 222, 268

39. Het verbod van bijstand in het stemhokje voor mensen met een verstandelijke functiebeperking laat ik hier terzijde, omdat deze kwestie minder relevant is voor het standstillbeginsel. Voor een beknopt overzicht, zie: Eijndhoven \& Goudsmit 2017, p. 668; W.A.E. Brüheim \& R. de Jong, 'Waarom mensen met een verstandelijke beperking geen recht hebben op ondersteuning bij het stemmen', NJB 2017/92, afl. 23, p. 1607. 
Het eerste aspect vormt een goed voorbeeld van het gestaag verwezenlijken van de langetermijnverplichtingen van het VN-verdrag Handicap. ${ }^{40}$ Op 1 januari 2019 trad het gewijzigde artikel $\mathrm{J} 4$ van de Kieswet in werking. Voor 2019 moest minstens $25 \%$ van de stemlokalen toegankelijk zijn. ${ }^{41}$ Vanaf 2019 moeten in principe álle stemlokalen toegankelijk zijn. ${ }^{42}$ Men kan echter wel beargumenteren dat de mogelijke uitzonderingen hierop te ruim geformuleerd zijn - met alleen een verantwoordingsplicht bij afwijking van de norm van toegankelijkheid - en dat zelfs een genereuze interpretatie van het VN-verdrag Handicap dergelijke uitzonderingen niet zou toelaten. ${ }^{43}$ Daarnaast bleek bij steekproeven in 2019 dat de volledige toegankelijkheid van stemlokalen in de praktijk juist terugliep in de twee maanden tussen de Provinciale Staten- en Waterschapsverkiezingen en de Europese verkiezingen. ${ }^{44}$ In die zin is het ook belangrijk dat, ondanks de vooruitgang qua regelgeving, de praktische toegankelijkheid niet alsnog terugloopt. Want ook de praktijk kan strijdig zijn met het standstillbeginsel. Zelfs nominale vooruitgang vraagt dus om oplettendheid.

Van de verkiezingen van 17 maart 2021 kan eveneens gezegd worden dat zij om (meer) oplettendheid vroegen. Ook al gold de eis van toegankelijkheid onverkort, was het aantal dagen om te stemmen verruimd en werd de mogelijkheid om mensen die bijstand behoeven uit het stemlokaal te verwijderen, geschrapt uit de uiteindelijke Tijdelijke wet verkiezingen covid-19, toch werd het kiesrecht van mensen met een functiebeperking wederom beperkt ten opzichte van relatief gezonde medemensen zonder dat het standstillbeginsel was meegewogen. ${ }^{45}$ Van veel mensen met een functiebeperking, die tot een of meer risicogroepen betreffende het coronavirus behoren, kon ook op de dagen voorafgaand aan 17 maart niet gevraagd worden om het risico te nemen om fysiek te gaan stemmen. ${ }^{46}$ Met het $\mathrm{VN}$-verdrag in de hand kan men namelijk beweren dat Nederland - zelfs met de crisisomstandigheden in aanmerking genomen de artikelen 10 en 11 onvoldoende naleefde door deze groep mensen met een functiebeperking aan dit extra risico bloot te stellen. ${ }^{47}$ Daarnaast bood de mogelijkheid tot machtigen geen volledig soelaas. Een aantal mensen met een functiebeperking had niemand om te machtigen. ${ }^{48}$ Daarenboven is er het principiëlere punt dat er op

40. Cera 2017b, p. 533-534

41. Hoegen Dijkhof 2017, p. 48

42. Stb. 2016,215, p. $2-3$.

43. Stb. 2016, 215, p. 3; Cera 2017b, p. 527, 533-534.

44. L.A. van Erk, J. Pothuis \& J. Hofstee, Review 'checklist toegankelijkheidscriteria stembureaus 2018', Amersfoort: Arcadis 2020, p. 4.

45. Stb. 2018, 483; Kamerstukken // 2020/21, 35590, nr. 20, p. 1.

46. P. van den Dool, 'OMT-leden bezorgd over besmettingsrisico tijdens verkiezingen', NRC Handelsblad 10 februari 2021, In het nieuws, p. 5.

47. Dijkstra 2020a, p. 378; G.C. Bruno, 'Article 11 [situations of risk and humanitarian emergencies]', in: V. della Fina, R. Cera \& G. Palmisano (red.), The UN-convention on the rights of persons with disabilities: a commentary, Cham: Springer 2017, p. 253-254.

48. Redactie NOS Nieuws, 'Rechtszaak over poststemmen: “Waarom moet ik mijn gezondheid op het spel zetten?"', NOS Nieuws 10 februari 2021, nos.nl. hen nu een grotere druk lag om hun stemgeheim op te geven vanmege hun functiebeperking. Het is dus voorstelbaar dat het alternatief van machtigen botst met de gelijke toegang tot het verkiezingsproces zoals dit gewaarborgd is in artikel $29 \mathrm{VN}$-verdrag Handicap. ${ }^{49}$ De beschreven achteruitgang van de toegankelijkheid van het verkiezingsproces voor mensen met een functiebeperking is dientengevolge verdedigbaar te kenmerken als potentieel strijdig met het standstillbeginsel. Het is daarom vreemd dat dit beginsel niet meegewogen lijkt te zijn door de wetgever. Daarnaast kwam het standstillbeginsel ook niet aan bod bij het kort geding waarin geëist werd dat de mogelijkheid voor 70-plussers om per post te stemmen ook werd uitgebreid naar jonge(re) mensen met een functiebeperking. ${ }^{50}$ Wellicht was er geen betere oplossing voor de toenmalige crisissituatie, maar het standstillbeginsel had mijns inziens een grotere - en expliciete - rol moeten spelen.

\subsection{Versobering onder het mom van zelfstandigheid}

Bij mijn analyse van de verkiezingen van 17 maart 2021 hing er veel af van de interpretatie van de verplichtingen in het VN-verdrag Handicap: was bijvoorbeeld machtigen wel of geen afdoende alternatief voor een toegankelijk verkiezingsproces? Dezelfde interpretatieproblematiek komen we tegen bij de kwestie of de invoering van en verdere verwikkelingen omtrent de Participatiewet al of niet stroken met het standstillbeginsel. Met andere woorden: worden de langetermijnverplichtingen uit het VN-verdrag Handicap met de Participatiewet naderbij gebracht of gebeurt juist het tegenovergestelde? Ik ben elders al dieper op deze wet ingegaan en zal mij hier beperken tot de hoofdlijnen. Mijn strikte doel hier is onderzoeken of deze hoofdlijnen anleiding geven voor de wetgever, de rechtspraak en (overige) beleidsmakers om het standstillbeginsel in ieder geval meer expliciete aandacht te geven bij hun verdere besluitvorming en uitspraken over de sociale zekerheid. ${ }^{51}$

De hierboven reeds genoemde doelen van het $\mathrm{VN}-$ verdrag Handicap - volwaardige deelname aan de maatschappij van mensen met een functiebeperking, die daarbij zo veel mogelijk zelfstandig hun eigen levenskeuzes maken - zijn bij uitstek relevant voor de sociale zekerheid. ${ }^{52}$ Veel mensen met een functiebeperking zijn namelijk afhankelijk van de sociale zekerheid voor hun

49. Cera 2017b, p. 533-535. Men kan aanvoeren dat dit soort kwesties niet de toegankelijkheid van het verkiezingsproces betreffen, maar dat het probleem ligt bij 'de laagdrempelige manier waarop in Nederland een volmacht kan worden verleend', zie: Brüheim \& De Jong 2017, p. 1607.

50. J. Verlaan, 'Partij voor de Dieren wil meer poststemmen', NRC Handelsblad 11 februari 2021, In het nieuws, p. 7; Rb. Den Haag 19 februari 2021, ECLI:NL:RBDHA:2021:1305; F. Bouma, 'Kabinet mag briefstemmen beperkt houden tot 70-plussers', NRC Handelsblad 19 februari 2021, In het nieuws, p. 2.

51. Dijkstra 2020b, p. 42-44.

52. Dit is onder andere uitgewerkt in art. 28 van het verdrag, zie: M. Fasciglione, 'Article 28 [adequate standard of living and social protection]', in: V. della Fina, R. Cera \& G. Palmisano (red.), The UN-convention on the rights of persons with disabilities: a commentary, Cham: Springer 2017, p. 523 
meest basale behoeften. ${ }^{53}$ Het verdrag is hier des te belangrijker omdat de rechten van de tweede generatie in de Grondwet meestal niet worden meegenomen bij de besluitvorming. ${ }^{54}$ Het VN-verdrag Handicap kan, in tegenstelling tot deze constitutionele rechten, wel door de rechter getoetst worden. ${ }^{55}$ De plicht voor verdragsstaten om volwaardige maatschappelijke deelname mogelijk te maken en zelfstandige levenskeuzes te faciliteren, laat echter een fikse ruimte wat betreft de invulling van de sociale zekerheid - hoewel er ontegenzeggelijk minimumeisen uit het verdrag naar voren komen. ${ }^{56}$ We zien dan ook dat opeenvolgende regeringen hun hervormingen van de sociale zekerheid inzake mensen met een functiebeperking (impliciet) presenteren als het naderbij brengen van deze doelen; dergelijke hervormingen dienden mensen met een functiebeperking namelijk zelfstandiger te maken. ${ }^{57}$ Toch is het aannemelijk te maken dat een aantal van deze hervormingen, waaronder de invoering en latere aanpassingen van de Participatiewet, geïnterpreteerd kunnen worden als versoberingen van de noodzakelijke voorzieningen voor de volwaardige maatschappelijke deelname van mensen met een functiebeperking. ${ }^{58}$ Daarmee zouden deze specifieke hervormingen eventueel strijdig kunnen zijn met het standstillbeginsel. Dat de Participatiewet als versobering kan worden gekenmerkt, heeft te maken met het idee van de participatiemaatschappij, dat inherent is aan deze wet, en de tweedeling tussen de beschikbare voorzieningen voor verschillende groepen mensen met een functiebeperking, die zich sinds de invoering van de Participatiewet steeds scherper aftekent.

Sinds 2015 is het grootste deel van de mensen met een functiebeperking die onder specifieke regelingen zoals de Wajong vielen, overgeheveld naar de one size fits all van de Participatiewet, die (bijna) alle mensen met afstand tot de arbeidsmarkt betreft. ${ }^{59}$ Veel mensen met een functiebeperking - vooral degenen met een zwaardere verstandelijke of lichamelijke functiebeperking - gingen hierdoor niet alleen achteruit in hun ver-

53. M.C. Nussbaum, Frontiers of justice: disability, nationality, species membership, Cambridge: Harvard University Press 2006, p. 73, 99, 415.

54. P.B.C.D.F. van Sasse van Ysselt, Realisering van grondrechten: de rechtsplicht van de overheid tot de verwerkelijking van grondrechten bij botsende rationaliteiten en belangen in een rechtspolitieke context (diss.), Amsterdam: Vrije Universiteit 2018, p. 140-147.

55. A.D. Belinfante \& J.L. de Reede, Beginselen van het Nederlandse staatsrecht, Deventer: Kluwer 2012, p. 209-212.

56. G. Palmisano, 'Article 19 [living independently and being included in the community]', in: V. della Fina, R. Cera \& G. Palmisano (red.), The UN-convention on the rights of persons with disabilities: a commentary, Cham: Springer 2017, p. 354-372; Fasciglione 2017, p. 510-524.

57. Kamerstukken I/ 2011/12, 33161, nr. 3, p. 1; C. van Ewijk, 'Kapitaalopbouw voor Zorg, zekerheid en pensioen', in: P. van Lieshout (red.), Sociale (on)zekerheid: de voorziene toekomst, Amsterdam: Amsterdam University Press 2016, p. 114; C. Kammer \& M. Beunderman, ‘Wederdienst voor bijstand omstreden', NRC Handelsblad 22 november 2019 , In het nieuws, p. 2.

58. Dijkstra 2020b, p. 42-44.

59. Kamerstukken I/ 2011/12, 33161, nr. 3, p. 3-4; P. van Echtelt, 'ledereen aan het werk? De beleidstheorie achter de Participatiewet', in: $\mathrm{H}$. Bosselaar (red.), Met andere ogen: onderzoekers over 5 jaar Participatiewet, Den Haag: Boom bestuurskunde 2020, p. 45 mogenspositie, maar werden ook onderworpen aan activerende maatregelen die hen de reguliere arbeidsmarkt op dienden te motiveren. ${ }^{60}$ Hierbij kan men denken aan de kostendelersnorm - waarbij het inkomen van gezinsleden meetelt om in aanmerking te komen voor bijstand - en het feit dat veel andere manieren om aan de samenleving bij te dragen buiten de arbeidsmarkt negatieve financiële gevolgen kunnen hebben. ${ }^{61}$ Deze activerende maatregelen hangen samen met de rol van de Participatiewet als sluitstuk van de sociale zekerheid: deze wet is er om mensen die kunnen werken, indien dat écht nodig is, tijdelijk te ondersteunen en hen tegelijkertijd richting betaald werk te bewegen. ${ }^{62}$ Binnen de participatiemaatschappij, die de overheid met de Participatiewet en soortgelijke hervormingen van de sociale zekerheid tot stand wil brengen, is het accent namelijk verschoven van het van overheidswege faciliteren van levensontplooiing naar het aanspreken van de eigen verantwoordelijkheid van de burger, die zo veel mogelijk zelfstandig dient te zijn. ${ }^{63}$ Mocht men alsnog meer steun behoeven, dan moet deze steun dientengevolge vanuit hun persoonlijke netwerk komen. ${ }^{64}$ Een groot aantal mensen met een functiebeperking dat nu onder de Participatiewet valt, komt echter zeer moeizaam aan een baan op de reguliere arbeidsmarkt, kan minder werken, verdient minder, ervaart vaak pijn en vermoeidheid bij werken, ontbeert regelmatig een sterk persoonlijk netwerk en heeft schier een dagtaak aan het regelen van hulp en voorzieningen om te functioneren. ${ }^{65}$ En daar worden zij in de participatiemaatschappij op afgerekend: zolang zij hulp behoeven worden zij, zoals Judith Jansen stelt, niet als volwaardig burger gezien en behandeld. ${ }^{66}$ Deze mensen worden nu zogezegd voor eeuwig geactiveerd, want zij zullen nooit onder de Participatiewet, en de daarin vervatte maatregelen om hen richting de reguliere arbeidsmarkt te motiveren, uitkomen. Daarmee betekenen deze maatregelen een achteruitgang in ondersteuning voor veel mensen met een functiebeperking ten opzichte van 2015 - toen zij nog onder regelingen zonder activerende elementen vielen - en ten opzichte van mensen die nog wél onder regelingen als de Wajong vallen - hoewel ook die laatste groep met versoberingen te maken heeft. ${ }^{67}$ Kortom, de verplichting uit het VNverdrag Handicap voor verdragsstaten om te faciliteren dat mensen met een functiebeperking volwaardig aan de maatschappij kunnen deelnemen en zo veel mogelijk

60. Van Echtelt 2020, p. 59; Centraal Planbanbureau, Position paper: hoofdlijnennotitie loondispensatie Participatiewet, Den Haag: Centraal Planbureau 2018, p. 3. Dijkstra 2020b, p. 43.

61. Boetzelaer-Gulyas 2021, p. 276, 282-283. Een deel van (de invulling van) deze activerende maatregelen kan verschillen per gemeente.

62. Boetzelaer-Gulyas 2021, p. 268.

63. J. Jansen, "De "verantwoordelijke beperkte": de beeldvorming van jonggehandicapten in de Participatiewet', in: H. Bosselaar (red.), Met andere ogen: onderzoekers over 5 jaar Participatiewet, Den Haag: Boom bestuurskunde 2020, p. 38-39; Van Echtelt 2020, p. 45-46.

64. C. Steinfeld, 'Lerende professionals in wijkteams', in: A.J. Kruiter, F. Bredewold \& M. Ham (red.), Hoe de verzorgingsstaat verbouwd wordt: kroniek van een verandering, Amsterdam: Van Gennep 2016, p. 81.

65. Dijkstra 2020b, p. 44.

66. Jansen 2020, p. 41.

67. Dijkstra 2020b, p. 44-45. 
eigen levenskeuzes kunnen maken, wordt met de Participatiewet minder gedegen vervuld dan voorheen. Sociale zekerheid wordt voor veel mensen met een functiebeperking beperkt en aan meer en strengere voorwaarden gebonden, die ook nog zwaarder op deze groep drukken door hun functiebeperking. Het is daarom denkbaar, zoals ik hierboven al poneerde, dat met de Participatiewet en soortgelijke hervormingen de verwezenlijking van de doelen en verplichtingen van het $\mathrm{VN}$ verdrag Handicap verder uit het zicht raakt en dat daarmee het standstillbeginsel wordt geschonden. ${ }^{68}$

Tijdens de besluitvorming rondom de Participatiewet lijkt het standstillprincipe zelden invloedrijk te zijn geweest, hoewel het op een blauwe maandag wel aan bod kwam - bijvoorbeeld in een (verworpen) amendement betreffende de kostendelersnorm. ${ }^{69}$ Dit laat zich wellicht verklaren vanuit de houding van de Nederlandse overheid ten opzichte van de tweede generatie rechten in het VN-Verdrag Handicap. De kosten van de daadwerkelijke verwezenlijking van de economische, sociale en culturele rechten werden opgegeven als reden om ratificatie uit te stellen en het optionele protocol aan ons land voorbij te laten gaan. ${ }^{70}$ Dit is vrij ironisch, aangezien het VN-verdrag Handicap juist paal en perk wilde stellen aan dergelijke kostenoverwegingen als maatstaf in hoeverre mensen met een functiebeperking volwaardig aan de maatschappij kunnen deelnemen. Juist in dat kader vormt het standstillbeginsel een belangrijke waarborg.

\section{Ter conclusie}

De belofte van het moderne mensenrechtenkader, waarmee deze bijdrage opende, is verre van verwezenlijkt voor mensen met een functiebeperking in Nederland. Dit geldt onder andere voor de hierboven geobserveerde achteruitgang inzake enkele van de langetermijndoelen en -verplichtingen die in het VN-verdrag Handicap zijn opgenomen. Van ten minste een deel van deze verzaking kan gezegd worden dat zij botst met de eisen van het standstillbeginsel en hier kan men Nederland als verdragsstaat op aanspreken. Uiteindelijk vraagt de situatie dat mensen met een functiebeperking hun rechten nog steeds niet volledig kunnen genieten simpelweg om meer aandacht van de Nederlandse overheid voor het VN-verdrag Handicap. Natuurlijk voor de verdragsverplichtingen, maar ook voor de general comments van het corresponderende VN-comité, de samenloop met andere verdragen en normen uit het internationale recht, zoals het in deze bijdrage besproken standstillbeginsel. ${ }^{71}$ In de huidige omstandigheden is het echter

68. Palmisano 2017, p. 354

69. Kamerstukken // 2018/19, 35174, nr. 9, p. 3.

70. J.R.E. Stolk, 'Het individueel klachtrecht bij het VN-comité voor de rechten van mensen met een beperking: slechts toekomstmuziek of ook nu al relevant?', Handicap \& Recht 2019/4, afl. 2, p. 35; Goldschmidt 2016, p. 8.

71. Dijkstra 2020a, p. 380; Dijkstra 2020b, p. 45. bijzonder moeilijk om deze noodzakelijke extra aandacht voor het verdrag in het algemeen, en het standstillbeginsel in het bijzonder, op de spreekwoordelijke kaart te zetten.

Dit komt, zoals hierboven al is opgemerkt, mede doordat Nederland zich niet heeft aangesloten bij het optionele protocol bij het VN-verdrag Handicap, wat een individueel en (in sommige gevallen) groepsgewijs klachtrecht bij het VN-comité mogelijk zou maken. ${ }^{72}$ Dit protocol is voorzien als een noodzakelijk internationaal complement voor het nationale toezicht op de uitvoering van het verdrag. ${ }^{73}$ Het nationale toezicht is in Nederland toegewezen aan het College voor de Rechten van de Mens. Hoewel dit college kan aansporen tot implementatie en naleving van het verdrag, kan het met zijn beperkt opgezette klachtenprocedure het protocollaire klachtenrecht waarschijnlijk niet volledig vervangen. ${ }^{74}$ Daarnaast zagen we dat die andere nationale waarborg voor het naleven van het verdrag, de rechtspraak, verzuimd lijkt te hebben om te wijzen op het standstillbeginsel als relevante zaken werden voorgelegd - voor zover dit op basis van mijn preliminaire onderzoek in de database Legal Intelligence en enkelvoudige concrete voorbeeld gezegd kan worden - zoals zij dat wel doet bij andere rechtsgebieden. Nu beide nationale veiligheidskleppen, het mensenrechtencollege en de rechtspraak, niet tot afdoende rechtsbescherming voor mensen met een functiebeperking hebben geleid, is het invoeren van een derde veiligheidsklep - oftewel het alsnog aansluiten bij het optionele protocol - wellicht het heroverwegen waard. Want zolang het standstillprincipe, met betrekking tot de verplichtingen die Nederland in het kader van het VN-verdrag Handicap is aangegaan, niet serieus wordt genomen, zullen mensen met een functiebeperking nog immer worden onttrokken aan het licht van het recht. ${ }^{75}$ 